\title{
A SUSTENTABILIDADE, O PREÇO DO TOMATE E O SALÁRIO MÍNIMO DO BRASIL ENTRE 1985 E 2015: UMA QUESTÃO DE SOBERANIA ALIMENTAR
}

\author{
Valquíria Duarte Vieira Rodrigues ${ }^{1}$ \\ Maria Izabel de Melo Oliveira dos Santos ${ }^{2}$
}

RESUMO:O artigo realiza análise de correlação entre o salário mínimo brasileiro e o preço do tomate entre 1985 e 2015 com fito de discutir o conceito de soberania alimentar e o direito de acesso à alimentação. $\mathrm{O}$ trabalho utiliza o método quantitativo para correlacionar 31 amostras de cada uma das variáveis. Realiza testes de correlação, de regressão linear e identificação de outliers por meio de gráficos de boxplot. Discute os resultados obtidos considerando o direito dos povos de ter acesso a alimentos vinculados à sua cultura.

PALAVRAS-CHAVES: Salário mínimo; Preço do tomate; Desenvolvimento rural; Direito à alimentação.

\section{ANALYSIS OF CORRELATION BETWEEN TOMATO PRICE AND MINIMUM WAGE IN BRAZIL FROM 1985 TO 2015: A FOOD SOVEREIGNTY ISSUE}

\begin{abstract}
The article analyzes the correlation between the Brazilian minimum wage and the tomato price between 1985 and 2015 in order to discuss the concept of food sovereignty and the right of access to food. The work uses the quantitative method to correlate 31 samples of each of the variables. Performs tests of correlation, linear regression and identification of outliers by means of boxplot graphs. It discusses the results obtained considering the right of the peoples to have access to food linked to their culture.
\end{abstract}

KEYWORDS: Minimum wage; Price of tomato; Rural development; Right to food.

\footnotetext{
${ }^{1}$ Mestranda em Agronegócio (PPAGRO) pela Universidade Federal de Goiás, Graduada em Ciências Contábeis pela Universidade Federal de Goiás, Professora na Universidade Estadual de Goiás (UEG). Contato: prof.valquiriaduarte@gmail.com.

${ }^{2}$ Mestre em Direito Agrário pela UFG/GO, Coordenadora do grupo de pesquisas História do Direito da Mulher. Coordenadora do curso de Direito do Centro Universitário Alves Faria - UNIALFA-GO.
} 


\section{INTRODUÇÃO}

A segurança alimentar sempre implica na necessidade de produção de alimentos em quantidade e com qualidade, na América do Sul, o Brasil lidera a produção de tomate, porém no cenário mundial sua participação é de apenas $5,5 \%$ da produção total de tomate. A sua cultura tem grande importância social e econômica em Goiás, sendo responsável por $75 \%$ da produção nacional, o que contribui para esse ser o maior produtor desta hortaliça (IBGE, 2004).

Para Guimarães (2003) o diagnóstico da segurança alimentar apontou que o problema brasileiro está assentado na absoluta falta de poder aquisitivo, ao contrário de outros países pobres, o Brasil não tem problemas quanto à oferta de alimentos, esses estão disponíveis, mas não são acessíveis à população de renda mais baixa.

O presente artigo discute a relação entre o preço do tomate e o salário mínimo brasileiro entre os anos de 1985 e 2015 sob a perspectiva da sustentabilidade a fim de avaliar os impactos sociais do reajuste anual do salário mínimo.

A discussão acerca da variação de preços decorrente do aumento do salário mínimo, analisada neste trabalho, se insere na dimensão intergeracional sustentabilidade na medida em que o reajuste anual do salário mínimo interfere na possibilidade de existência digna de camadas mais pobres da população.

O conceito de soberania alimentar foi cunhado a partir das discussões feitas pela Via Campesina (2001) e diz que a fome e desnutrição estão atrelados às políticas agrícolas e comerciais sobre as quais interferem grandes corporações ansiosas por manter o patamar de ganhos que ostentam. A soberania alimentar seria obtida por meio da análise do campo a fim de estabelecer políticas públicas que atendam ao desenvolvimento local por meio de cultura de gêneros agrícolas adaptados a cada região e que integrem a cultura alimentar das populações.

Neste aspecto, o tomate constitui importante componente da cesta básica nacional do brasileiro consoante dados do Departamento Intersindical de Estatística e Estudos Socioeconômicos (DIEESE). Entre os legumes da cesta básica estabelecida pelo Decreto Lei n. 399, de 1938, a quantidade média anual de tomate perfaz 9 quilos, o que supera todos os outros componentes, inclusive a carne, com 6 quilos anuais, o feijão, com 4,5 quilos e o arroz, com 3 (DIEESE, 2016).

Devido à sua importância na composição da alimentação básica da população brasileira, foi escolhido o tomate como variável de análise da relação possivelmente existente entre a variação do salário mínimo e o preço do alimento. De fato, trata-se de fruta originária 
da América Latina que ganhou notoriedade após as grandes navegações dos séculos XIV e XV quando os europeus se encarregaram de sua divulgação no velho continente (SANTILI, 2009).

Parte-se da hipótese que o aumento do salário mínimo não importa necessariamente ganhos de qualidade de vida e incremento no poder de compra do trabalhador. Acredita-se que, a partir da correlação que se estabelecerá por meio do uso do software Statistical Package for the Social Sciences (SPSS Statistics), seja possível verificar se o preço do alimento acompanha ou não o nível de aumento concedido anualmente ao salário mínimo. Logo, o preço do tomate será colocado como variável dependente do valor do salário mínimo (variável independente).

Caso os reajustes de preços do tomate sigam o valor do salário mínimo, restará demonstrado que o aumento do salário mínimo não redunda em ganhos reais ou aumento do poder de compra dos trabalhadores que percebem este vencimento. Confirmando-se esta hipótese, será necessário propor novos encaminhamentos à pesquisa a fim de estabelecer parâmetros que permitam discutir a relação existente entre a renda mínima do trabalhador brasileiro e o valor dos alimentos que são direcionados à sua mesa.

Este tipo de discussão se insere no debate acerca da eficiência das políticas públicas de amparo mínimo ao cidadão, uma vez que, o salário mínimo constitucionalmente definido deve atender ao mínimo existencial. Como direito de segunda dimensão (BOBBIO, 2004), é mister que o salário mínimo do trabalhador seja suficiente para " [...] atender a suas necessidades vitais básicas e às de sua família com moradia, alimentação, educação, saúde, lazer, vestuário, higiene, transporte e previdência social, com reajustes periódicos que lhe preservem o poder aquisitivo" (art. $7^{\circ}, \mathrm{IV}$, da Constituição Federal).

A estipulação de salário mínimo conforme o princípio da dignidade humana e que permita o exercício da cidadania bem como o respeito ao cidadão e seus padrões alimentares é dever do Estado (BARROSO, 2009). Logo, justifica-se a escolha das variáveis de que ora se trata e acredita-se ser possível avaliar a relação entre elas com auxílio dos conhecimentos provenientes da Estatística e do Direito.

\section{REFERÊNCIAL TEÓRICO}

A noção malthusiana de que a produção de alimentos chegará a ponto em será impossível alimentar a população mundial impulsionou os debates que culminaram na revolução verde. Todavia, a preocupação com a produtividade agrícola motivou o desenvolvimento de estratégias tecnológicas desde tempos pré-históricos (MAZOYER; ROUDART, 2010). 
E, enquanto no século XX, o conceito de segurança alimentar serviu para discutir a capacidade dos países de produzir o suficiente para alimentar suas populações, o século XXI coloca em debate a qualidade dos alimentos consumidos. Estudos a respeito da desnutrição conduziram à definição de requisitos necessários a uma dieta saudável, e à identificação de relevante número de pessoas desnutridas em países considerados desenvolvidos (CHONCHOL, 2005).

Em 1983, o conceito de segurança alimentar foi reformulado pela FAO, que passou a considerar que haveria segurança alimentar quando todas as pessoas tivessem, a todo tempo, acesso físico e econômico a alimentação básica que lhes fosse necessária. Os objetivos específicos de uma política de segurança alimentar mundial estariam relacionados à produção em países de baixa renda, manutenção dos níveis dos estoques e facilitação do acesso de povos necessitados aos alimentos (FAO, 1985).

A partir dos anos 1990, o debate a respeito da segurança alimentar foi retomado em razão do temor de que condições ecológicas como o aquecimento do planeta, o desmatamento de florestas tropicais e a erosão genética poderiam ameaçar a disponibilidade de alimentos. Além disso, passou-se a considerar a influência de questões políticas no abastecimento, já que algumas regiões (América Latina e Caribe) não obtiveram muito sucesso no incremento da oferta de alimentos ou tiveram sua disponibilidade reduzida, como ocorreu na África Subsaariana.

Em 1996, quando foi publicada a Declaração de Roma sobre Segurança Alimentar, a FAO reconheceu a pobreza, a existência de conflitos, terrorismo, corrupção e degradação do ambiente como causas de insegurança alimentar. Houve o comprometimento dos signatários para empregar esforços suficientes a reduzir pela metade o contingente de pessoas famintas (FAO, 1996).

De acordo com a Via Campesina, todos os países e todos os povos possuem direito e a capacidade suficiente para definir suas próprias políticas agrárias e alimentares. Portanto, cabe a cada país e cada povo proteger seus mercados internos e formar reservas destinadas à agricultura, incluindo-se aí a possibilidade de fornecimento de subsídios aos pequenos produtores (VIA CAMPESINA, 2011).

Nesse ponto, convém destacar que o método de avaliação de segurança alimentar da FAO utiliza informações fornecidas por cada país a respeito de seus estoques, produção, importação, exportação e desperdício. Para avaliar a adequação da quantidade de calorias disponíveis per capita, este método requer como parâmetros informações que são normalmente 
derivadas de pesquisas de orçamentos domésticos: a ingestão calórica média, o coeficiente de variação desta ingestão (para obter a distribuição do consumo de energia) e o valor de referência (ou ponto de corte) que estabelece a necessidade calórica mínima per capita. Entre as vantagens desse método está o seu custo razoável, além, de frequente atualização dos dados, sendo possível analisar as tendências da disponibilidade calórica per capita nos países ao longo do tempo (PESSANHA; VANNIER-SANTOS; MITCHELL, 2016).

As desvantagens do método da FAO decorrem de se basear em informações que tem alto grau de imprecisão, oriundas, por exemplo, dos dados da produção, em conferir mais importância ao consumo médio de energia do que a distribuição desta energia, a utilização, de informações agregadas no nível nacional acarreta ainda mais uma desvantagem. Nem mesmo a desagregação das informações em nível regional ou por subgrupos segundo a idade e o sexo das pessoas é factível. (PESSANHA; VANNIER-SANTOS; MITCHELL, 2016).

Não sem razão a estimativa da FAO foi designada para a supervisão do número de pessoas subnutridas com fito de atingir a meta estipulada pela Cúpula Mundial da Alimentação de 1996. É uma informação importante na tomada de decisão em nível nacional e global. Todavia, sabendo-se que a insegurança alimentar consiste antes em concentração em de disponibilidade do que em produtividade, faz-se necessário avaliar a distribuição de frequências ou percentagens a partir de dados derivados de pesquisas por amostragem. A balança de alimentos deve ser integrada qualidade da alimentação (soberania alimentar) e e não apenas pelas quantidades de toneladas de grãos e proteína animal (PESSANHA; VANNIER-SANTOS; MITCHELL, 2016).

Os programas voltados à agricultura, possibilitaram um aumento na produção de alimentos e uma diminuição na variabilidade de fornecimento de alimentos insuficientes para uma vida saudável. Entre estes programas, destacam-se o PRONAF, o PAA e o PNAE, que oferecem crédito aos agricultores e estipulam políticas de comercialização da produção. Apesar de esses programas auxiliarem a manutenção da renda, no tentanto, alguns sofrem ameaça de descontinuidade a partir da ascenção do Presidente Michel Temer ao poder (ALMEIDA et al, 2018).

Incumbe ao Estado considerar seu papel na promoção destas medidas e no controle de padrões de qualidade na alimentação. É necessário considerar que nem toda redução em custo de produção ou celeridade na aprovação de transgênico ou agrotóxico será suficiente para trazer benefícios à população. A depender da medida que se toma, é mesmo possível que se traga mais malefícios do que benefícios a longo prazo. É o caso, por exemplo da discussão que 
se faz por meio dos projetos de lei que discorre sobre o trabalho no meio rural e sobre a aprovação de novos insumos agrícolas.

O debate sobre os direitos humanos deve integrar ao aspectos relacionados à agricultura de base camponesa, que muito tem a contribuir para a economia e para o desenvolvimento sustentável. Além disso, políticas públicas de promoção de agricultura no campesinato são formas de assegurar a fixação de pessoas no campo, permitir o acesso a bens e serviços, retendo a inflação e a vulnerabilidade a aumento de preços em áreas rurais. A padron ização e a determinação de monopólios a partir de políticas públicas direcionadas ao agronegócio acaba por agravar os problemas já existentes, criando ciclos incansáveis de questão agrária que interfere negativamente na sustentabilidade e no desenvolvimento (CÂNDIDO et al, 2018).

\section{METODOLOGIA}

A despeito de este trabalho se pautar em uso de metodologia quantitativa, uma vez que visa avaliar a dados que podem ser expressos numericamente por meio de técnicas de conhecimento estatístico, também foi elaborada pesquisa qualitativa. Ocorre que a vinculação da discussão ao conceito de soberania alimentar envolve aspectos do comportamento, da subjetividade e da cultura humana que não podem ser compreendidos sem o auxílio do método qualitativo (MARCONI; LAKATOS, 2000).

Para realização do trabalho, foi efetivada aplicação estatística dos dados em testes de correlação e regressão que permitem avaliar a existência de relações lineares entre as variáveis. É possível, por meio destes testes, medir eventuais correlações e determinar com nível de confiança de $95 \%$ o grau de influência de uma variável sobre a outra.

Após a seleção das variáveis, foram obtidos os dados das séries históricas de valores anuais do preço do tomate e do salário mínimo. O preço do tomate está disponível para consulta na base de dados do Instituto de Pesquisa Econômica Aplicada (IPEA), por meio de sua base de dados disponível ao público em ambiente virtual (IPEADATA). Foram selecionados os dados de 1985 até 2015, que são os números mais recentes aos quais foi possível obter acesso. Os valores utilizados são expressos em reais após conversão realizada manualmente.

Já os dados referentes ao salário mínimo foram obtidos por meio de consulta ao endereço eletrônico do DIEESE (2018). Entre os anos de 1985 e 1993, foram identificadas situações em que foi estabelecido mais de um valor ao longo do ano. Nestes casos, fez-se a 


\section{A SUSTENTABILIDADE, O PREÇO DO TOMATE E O SALÁRIO MÍNIMO DO BRASIL ENTRE 1985 E 2015: UMA QUESTÃO DE SOBERANIA ALIMENTAR}

média dos valores por meio do EXCEL e, em seguida, realizou-se a conversão das moedas a fim de que todos os valores correspondessem à moeda corrente.

A análise de correlação tem como objetivo a obtenção do valor que indica o nível de relacionamento linear existente entre as duas variáveis (HOFFMANN, 2015). Foram utilizadas 31 amostras. Esta quantidade de amostras permite a utilização da Tabela Normal, pois a distribuição das médias amostrais se torna mais próxima da curva normal, à medida que aumenta a quantidade de amostras, independentemente do formato de distribuição de dados populacionais (TRIOLA, 1999).

O cálculo de r é obtido através da formula seguinte:

$$
r=\frac{n\left(\sum X Y\right)-\left(\sum X\right)\left(\sum Y\right)}{\sqrt{\left[n \sum X^{2}-\left(\sum X\right)^{2} \mid n \sum Y-\left(\sum Y\right)^{2}\right]}}
$$

\footnotetext{
Sendo:

$\mathrm{Y}=$ valores dispostos no eixo vertical;

$\mathrm{a}=$ ordenada à origem, ou intercessão no eixo dos Y;

$\mathrm{b}=$ coeficiente angular;

$\mathrm{X}=$ valores dispostos no eixo horizontal;

$\mathrm{n}=$ número de períodos observados;

$r=$ Índice de correlação.
}

A análise de correlação possibilita identificar se uma variável sofre interferência de outra. Para aferir a existência de correlação, é necessário avaliar o coeficiente de Pearson. Quanto mais próximo o coeficiente de Pearson estiver do número 1, mais marcante será a correlação existente entre as variáveis analisadas (TRIOLA, 1999).

Figueiredo Filho e Silva Junior (2009) afirmam que, quando o cálculo do coeficiente de Pearson sofre interferência de outliers, compromete-se o resultado do teste. A fim de verificar se existe algum dado que apresente disparidade em relação aos demais, ou seja, um outlier, foram produzidos os seguintes gráficos em formato de Boxplot por meio do uso do SPSS Statistics. Veja-se: 


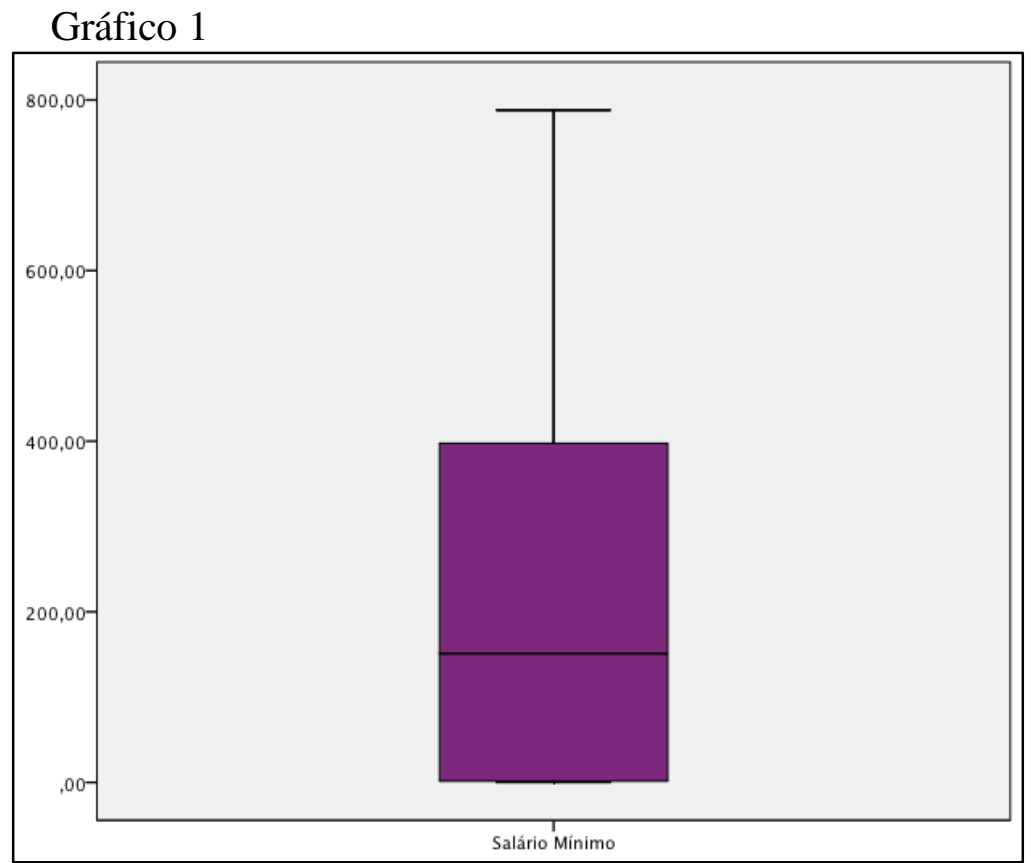

Fig. 1: Boxplot, fonte: Elaborada pelos autores/2018.

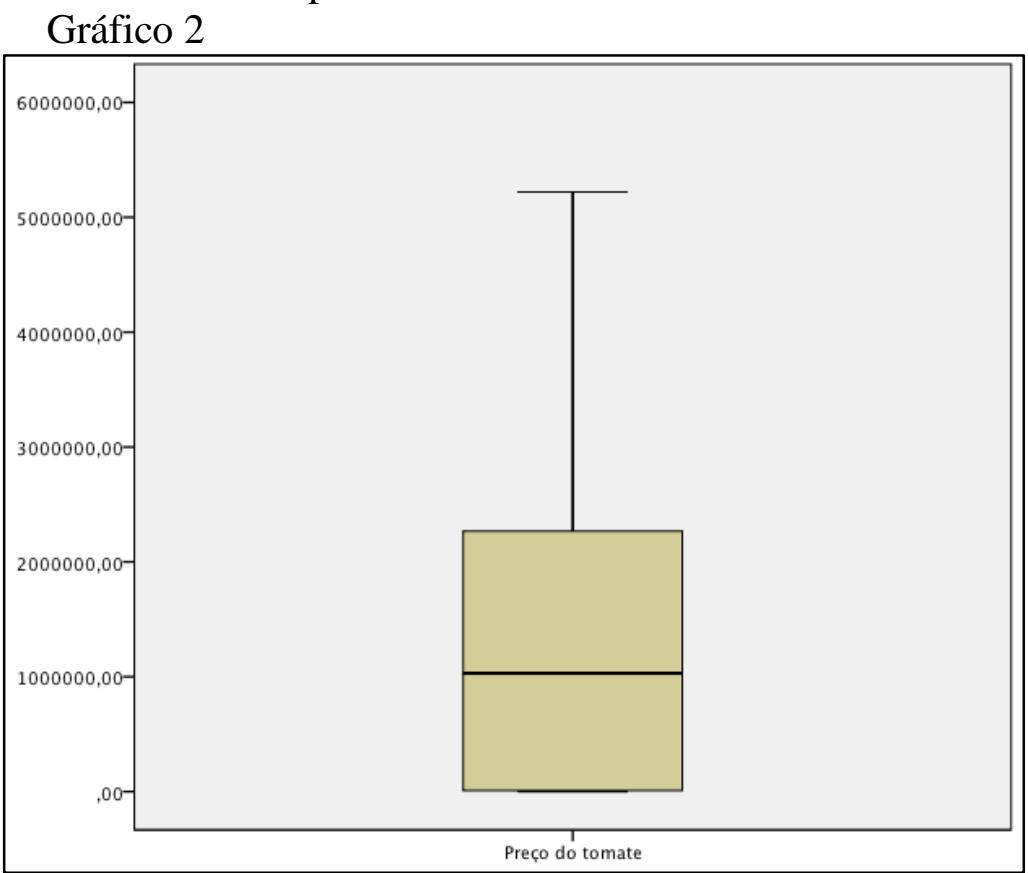

Fig. 2: Boxplot, fonte: Elaborada pelos autores/2018.

Os outliers são valores extremos que apresentam disparidade notável em relação aos demais dados coletados na amostra (TRIOLA, 1999).

Percebe-se, pela análise dos gráficos que não há outliers entre os dados coletados. Caso fossem encontrados outliers poder-se-ia distorcer o valor médio das amostras. Isto interferiria no valor obtido quando do cálculo de coeficiente de correlação, distorcendo-o. Logo, os outliers interferem negativamente na realização dos cálculos de correlação e podem 


\section{A SUSTENTABILIDADE, O PREÇO DO TOMATE E O SALÁRIO MÍNIMO DO BRASIL ENTRE 1985 E 2015: UMA QUESTÃO DE SOBERANIA ALIMENTAR}

comprometer a pesquisa por meio da aceitação ou refutação inadequada de hipóteses (FIGUEIREDO FILHO; SILVA JÚNIOR, 2009).

Considerando-se o fato de que existe correlação linear entre as duas variáveis submetidas ao teste de hipóteses, desenvolveu-se a equação de y em função de x por meio da regressão linear. A análise de regressão se estabelece em conformidade com uma equação que descreve o comportamento de uma variável (dependente) em relação à outra (independente). A expressão matemática que expressa esta reta é $\bar{y}=a+b x$, em que $a$ é o intercepto de $y$ e $b$ é a inclinação. Para encontrar $b_{0}$ e $b_{1}$ têm-se seguintes as fórmulas:

$$
\begin{gathered}
b=\frac{n\left(\sum X Y\right)-\left(\sum X\right)\left(\sum Y\right)}{n\left(\sum X^{2}\right)-\left(\sum X\right)^{2}} \\
a=\frac{\sum Y-b\left(\sum X\right)}{n}
\end{gathered}
$$

O coeficiente de correlação (r) pode ser associado ao coeficiente de determinação (R quadrado), a fim de permitir avaliar em que medida a variação de y (variável dependente) é consequência de alterações sofridas pela variável independente (x) (HOFFMANN, 2015).

\begin{tabular}{|c|c|c|c|c|c|c|c|c|c|c|}
\hline \multirow{2}{*}{ Modelo } & \multirow{2}{*}{$\mathrm{R}$} & \multirow{2}{*}{$\begin{array}{c}\mathrm{R} \\
\text { quadrado }\end{array}$} & \multirow{2}{*}{$\begin{array}{l}\text { R quadrado } \\
\text { ajustado }\end{array}$} & \multirow{2}{*}{$\begin{array}{c}\text { Erro padrão } \\
\text { da } \\
\text { estimativa }\end{array}$} & \multicolumn{5}{|c|}{ Estatísticas de mudança } & \multirow{2}{*}{$\begin{array}{l}\text { Durbin } \\
\text { Watson }\end{array}$} \\
\hline & & & & & $\begin{array}{l}\text { Mudança de } \\
\text { R quadrado }\end{array}$ & $\begin{array}{c}\text { Mudança } \\
\text { F }\end{array}$ & gl1 & $\mathrm{gl} 2$ & $\begin{array}{c}\text { Sig. } \\
\text { Mudança } F\end{array}$ & \\
\hline 1 & $0,983^{\mathrm{a}}$ & 0,966 & 0,964 & $\begin{array}{c}295204,0 \\
19572882 \\
500000\end{array}$ & 0,966 & 812,277 & 1 & 29 & 0,000 & 1,555 \\
\hline
\end{tabular}

Tabela 1 - Sumarização do modelo

a. Preditores: (Constante), Salário Mínimo

Fig. 3: Sumarização do modelo, fonte: Elaborada pelos autores/2018. 
O teste de Durbin-Watson ${ }^{3}$ é utilizado para atestar a existência de autocorrelação nos resíduos da regressão. A existência de correlação das amostras analisadas neste trabalho pode ser identificada pelo fato de o índice obtido ser superior ao valor de R-quadrado.

De acordo com Brooks (2002), a autocorrelação dos resíduos se verifica quando uma ou mais variáveis explicativas não compõe a modelagem pesquisada. Isto acaba por incorporar os resíduos aos efeitos dessas variáveis, e prejudica a qualidade do modelo de regressão. O chamado "enviesamento" dos coeficientes pesquisados e resulta em distorções no desvio padrão e no coeficiente de determinação (R-quadrado).

Para descartar a ocorrência de problemas com autocorrelação dos resíduos, existe uma tabela que indica valores críticos do teste de Durbin-Watson, quando são submetidas 2 à análise. No caso de análise de 31 amostras, se o valor do coeficiente se encontrar entre 1,085 e 1,345, possível descartar a autocorrelação. O valor obtido perfaz 1,555, estando, portanto, muito próximo ao valor do intervalo. O fato de o coeficiente de Durbin-Watson ser superior ao valor de R-quadrado também indica que é possível excluir a autocorrelação.

\section{RESULTADOS E DISCUSSÃO}

Em 2009, a quantidade de pessoas famintas no planeta atingiu a histórica marca de 1 bilhão de pessoas. O número sofreu decréscimo desde então, mas, ainda assim, em 2016, 815 milhões de pessoas ainda passavam fome no mundo (FAO, 2017) ${ }^{4}$.

A redução na quantidade de pessoas famintas é atribuída à redução do preço dos alimentos e amenização da crise econômica de 2009 (FAO, 2010). Todavia, a FAO reconhece que o número de afetados pela fome é bastante alto, e considera inaceitável o aumento da quantidade de pessoas que sofrem em virtude de fome estrutural. Questiona-se acerca das razões que ainda fazem da falta de alimentos um dos grandes problemas que afligem a humanidade.

\footnotetext{
3 "A validade do teste depende de os erros terem distribuição normal com média zero e variância constante e das variáveis explanatórias não serem aleatórias. Devemos ressaltar que não se deve aplicar o teste de Durbin-Watson quando há variáveis explanatórias aleatórias, como é o caso de modelos onde valores de $\mathrm{Y}$ defasados aparecem entre as variáveis explanatórias. Nestes casos, outros testes devem ser usados" (HOFFMANN, 2015, p. 284-285). ${ }^{4}$ Conforme relatório da Food Security Information Network, 124 milhões de pessoas de 51 países passaram por crises de insegurança alimentar em 2017. Em 2016, este número perfazia 108 milhões de pessoas em 48 países em situação reconhecidamente crítica. Em 2015, o total de famintos ou desnutridos no mundo era 777 milhões de pessoas.
} 
A fome não é tanto a consequência de uma produção alimentar insuficiente, como da marginalização econômica de certas populações. Consequentemente, a prioridade não é tanto aumentar a produção dos que já produzem muito, mas dar a todos os meios necessários para produzir (CHONCHOL, 2005, p. 34-35).

A fome e a desnutrição são causadas, não por desastres naturais, secas e acidentes geográficos, mas pelas políticas agrícolas e comerciais que não levam em conta o direito de acesso a alimentos saudáveis e culturalmente adequados aos hábitos das populações (VIA CAMPESINA, 2001).

Amartya Sen (2010) entende o desenvolvimento como um processo decorrente da expansão das liberdades desfrutadas pelas pessoas de modo real. Para obter situação de desenvolvimento, seria necessário, portanto, remover causas de privação de liberdade como a pobreza, a fome, a tirania, a ausência de serviços públicos básicos, a intolerância, entre outros. A riqueza é vista por Amartya Sen (2010) como um dos fatores a serem considerados na avaliação de desenvolvimento porque o poder econômico permite acesso a itens como educação, saúde e alimentação. Mas a simples consideração da pobreza como elemento definidor do desenvolvimento redunda em generalizações que impedem a compreensão de outros fatores que envolvem as políticas públicas.

Ainda assim, a elevação da renda de comunidades rurais, que possibilita também a elevação do acesso à educação e saúde, depende do aproveitamento de aspectos vinculados ao patrimônio cultural e natural em suas peculiaridades (VEIGA, 2002).

No caso das medidas de reajuste anual do salário mínimo, no entanto, o aumento não importa aumento de renda do trabalhador, uma vez que atrelado ao índice de inflação e ao produto interno bruto. Os reajustes periódicos de que trata o art. $7^{\circ}, \mathrm{IV}$, da Constituição Federal visam preservar o poder aquisitivo do salário que permite o mínimo existencial.

Não há nesta decisão, política que diga respeito a incremento de renda do trabalhador. Ao contrário, os reajustes são acompanhados pelo aumento dos preços dos itens de primeira necessidade, como o tomate, por exemplo. Conforme ficou demonstrado, o preço do tomate seguiu a tendência imposta pelo aumento do salário mínimo. Neste prisma, o aumento do salário mínimo não pode ser considerado como medida de soberania alimentar ou mesmo de segurança alimentar, pois não permite ao cidadão incrementar seu acesso aos alimentos de que necessita.

A tabela a seguir expressa os resultados obtidos no teste de correlação realizado no SPSS Statistics, observe-se: 
Tabela 2 - Correlações

\begin{tabular}{|ll|c|c|}
\hline & & Salário Mínimo & Preço do tomate \\
\hline Salário Mínimo & $\begin{array}{l}\text { Correlação de } \\
\text { Pearson } \\
\text { Sig. (bilateral) }\end{array}$ & 1 & $0,983^{* *}$ \\
& N & 31 & 0,000 \\
Preço do tomate & Correlação de & $0,983^{* *}$ & 31 \\
& $\begin{array}{l}\text { Pearson } \\
\text { Sig. (bilateral) }\end{array}$ & 0,000 & \\
N & 31 & 31 \\
\hline
\end{tabular}

**. A correlação é significativa no nível 0,01 (bilateral).

Fig. 4: Tabela do teste de correlação, fonte: Elaborada pelos autores/2018.

No caso do teste realizado para verificar a correlação entre o salário mínimo e o preço médio anual do tomate, o valor para o coeficiente de correlação de Pearson obtido foi 0,983. Isto permite afirmar que o preço do tomate pode ser relacionado à variação ocorrida no valor do salário mínimo nacional.

Considerando-se que o coeficiente de correlação de Pearson como "[...] medida de associação linear entre variáveis" (FIGUEIREDO FILHO; SILVA JÚNIOR, 2009, p. 118), entende-se que a correlação deriva do compartilhamento da variância dos aspectos analisados. E o fato de que a análise feita neste trabalho apresentou número bastante próximo a 1 evidencia a existência de relação de dependência entre o preço do tomate e o valor do salário mínimo.

A partir dos dados coletados, também foi possível estabelecer o Gráfico de Regressão linear que pode ser observado a seguir. A equação de regressão, constante no Gráfico 3, permite realizar predições quando há correlação linear significativa (TRIOLA, 1999). 


\section{A SUSTENTABILIDADE, O PREÇO DO TOMATE E O SALÁRIO MÍNIMO DO BRASIL ENTRE 1985 E 2015: UMA QUESTÃO DE SOBERANIA ALIMENTAR}

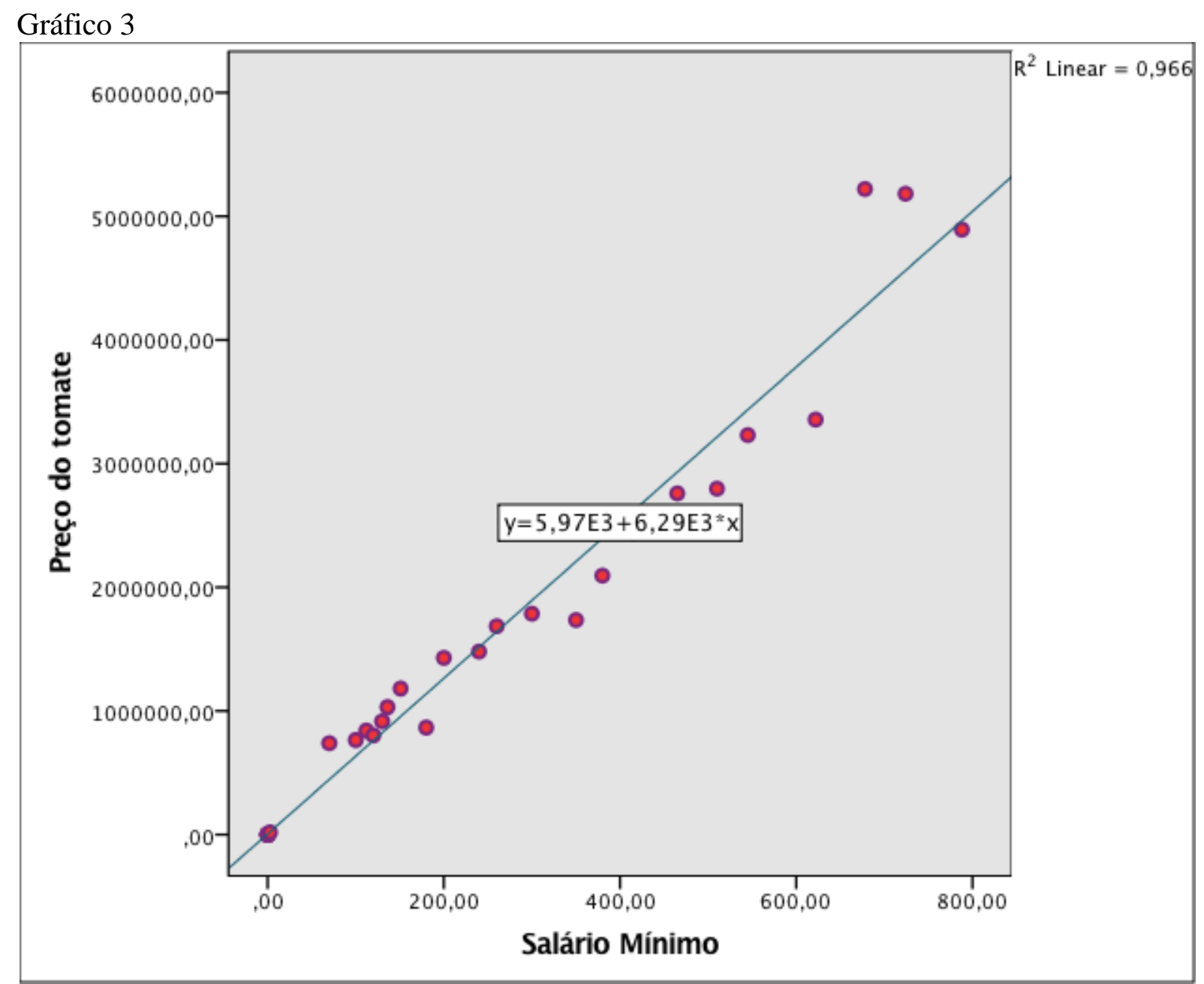

Fig. 5: Gráfico de Regressão, fonte: Elaborada pelos autores/2018.

No Gráfico 3, a variável x expressa o valor do salário mínimo (variável independente), enquanto a variável independente (y) remete ao preço do tomate. De fato, como se pode verificar o aumento do salário mínimo, estatisticamente, explica a variação do preço do alimento em $96,6 \%$ dos casos pesquisados.

\section{CONSIDERAÇÕES FINAIS}

O trabalho partiu da hipótese de que, em análise de correlação, o preço do tomate é variável dependente do valor do salário mínimo. Assim, o nível de aumento concedido anualmente ao salário mínimo tem reflexos sobre o preço do tomate. O preço do tomate será colocado como variável dependente do valor do salário mínimo (variável independente).

Verificados os dados, identificou-se que os reajustes de preços do tomate seguem o valor de venda do tomate, o que demonstra que o aumento do salário mínimo não redunda em 
ganhos reais ou aumento do poder de compra dos trabalhadores que percebem este vencimento. Percebe-se que a ideia de acesso aos alimentos, o que é muito distinto de disponibilidade de alimentos, seja por problemas de renda, ou seja devido a outros fatores como conflitos internos, ação de monopólios ou mesmo desvios.

Considerando o conceito de soberania alimentar, destaca-se que o aumento do salário mínimo acaba provocando como consequência o aumento do preço dos alimentos e, possivelmente em outros produtos. A alta no preço dos alimentos provoca consequenc

Confirmada a hipótese inicialmente proposta, é preciso apresentar novos encaminhamentos à pesquisa a fïm de estabelecer parâmetros que permitam discutir a relação existente entre a renda mínima do trabalhador brasileiro e o valor dos alimentos que são direcionados à sua mesa. Com este intuito, acredita-se que será necessário em futuros estudos avaliar os demais componentes da cesta básica, bem como outros itens que perfazem o cotidiano das famílias, tais como gasolina e gás de cozinha.

Avaliando estes itens será mais seguro avaliar a interferência do reajuste anual do salário mínimo na possibilidade de acesso a alimentos, bens e serviços. Considerando o conceito de soberania alimentar, destaca-se que o aumento do salário mínimo acaba provocando como consequência o aumento do preço dos alimentos e, possivelmente em outros produtos. A alta no preço dos alimentos, por si, implica variações no preço de outros itens que ficam mais caros e, portanto, menos acessíveis à população de baixa renda.

As pessoas mais pobres se veem diante da difícil escolha entre a compra de um alimento e o pagamento por bens como vestuário, eletrodomésticos e outros dos quais depende a economia urbana, mas que atingem o meio rural de modo bastante cruel se se levar em conta a natural dificuldade de aquisição destes bens pelas pessoas do campo. O campo enfrenta problemas logísticos e de disponibilidade de itens e serviços já conhecidos da Academia e do público em geral.

A mesma peça de vestuário vendida numa capital custa consideravelmente mais ao consumidor final do que se paga em uma capital. Os serviços seguem a mesma tendência, pois o custo de vida também lhes implica variações.

O reajuste anual do salário mínimo constitui política virtual de recomposição das perdas salariais decorrentes da inflação e não se presta a atender à soberania alimentar e à sustentabilidade nas políticas de produção de alimentos e de promoção de melhorias na qualidade de vida. Na verdade, diante da realidade que impõe a competitividade do mercado, produtores tendem a buscar toda sorte de medida para reduzir os custos de produção. E chega- 
se ao cúmulo, no século XXI, de se defender o uso de agrotóxicos como se defende um remédio, como fez o candidato a presidente, Geraldo Alkmin, na campanha de 2018.

\section{REFERÊNCIAS}

ALMEIDA, Mariza de et al. Análise dos efeitos das políticas públicas de segurança alimentar e nutricional a partir de indicadores da FAO/Analysis of the effects of public food and nutritional security policies based on FAO indicators. Brazilian Journal of Development, v. 4, n. 2, p. 642-654, 2018.

BARROSO, Luis Roberto. Curso de Direito Constitucional: os conceitos fundamentais e a construção do novo modelo. São Paulo: Saraiva, 2009.

BOBBIO, Norberto. A era dos direitos. 7. ed. Rio de Janeiro: Elsevier, 2004.

BROOKS, Chris. Introductory Econometrics for Finance. New York: Cambridge University Press, 2002.

CANDIDO, João Ernesto Pelissari et al. Soberania e segurança alimentar: uma análise para o fortalecimento da cultura alimentar/Sovereignty and food security: an analysis for the strengthening of food culture. Brazilian Journal of Development, v. 4, n. 7, p. 3821-3829, 2018 .

CHONCHOL, Jacques. A soberania alimentar. Estudos Avançados. São Paulo, v. 55, n. 19, p. 33-48, Set-dez. 2005.

DIEESE. Metodologia da cesta básica de alimentos. São Paulo, 2016. Disponível em: <https://www.dieese.org.br/metodologia/metodologiaCestaBasica2016.pdf >. Acesso em: 10 jun. 2018.

Salário mínimo nominal e necessário. São Paulo, 2018. Disponível em: <https://www.dieese.org.br/analisecestabasica/salarioMinimo.html>. Acesso em: 10 jun. 2018.

FAO. FAO: the first 40 years. Roma, 1985.

.The state of food insecurity in the world: addressing food insecurity in protracted crises. Roma, 2010. Disponível em: 〈http://www.fao.org/docrep/013/i1683e/i1683e.pdf>. Acesso em: 18 maio 2017.

.The state of food security and nutrition in the world: building resilience for peace and food security. Roma: FAO, 2017. Disponível em: 〈http://www.fao.org/3/a-I7695e.pdf〉. Acesso em: 2 jun. 2018.

FIGUEIREDO FILHO, Dalson Britto; SILVA JÚNIOR, José Alexandre. Desvendando os mistérios do coeficiente de correlação de Pearson (r). Revista Política Hoje. [S.1.], v. 18, n. 1, p. 115-146, 2009.

GUIMARÃES, O. Arroz, feijão e leite são insuficientes para tanta gente. Valor Econômico, São Paulo: 12 de maio de 2003 pag. F2, 2003. 
HOFFMANN, Rodolfo. Análise de regressão: uma introdução à econometria. Piracicaba: ESALQ/USP, 2015.

IPEADATA. Preço do tomate: frequência anual de 1947 até 2015. Rio de Janeiro, 2017. Disponível em: <http://www.ipeadata.gov.br/Default.aspx>. Acesso em: 2 jun. 2018.

MARCONI, Marina de Andrade; LAKATOS, Eva Maria. Metodologia Científica. 3. ed. São Paulo: Atlas, 2000.

MAZOYER, Marcel; ROUDART, Laurence. História das agriculturas no mundo: do neolítico à crise contemporânea. São Paulo: UNESP; Brasília, NEAD, 2010.

PESSANHA, Lavínia; VANNIER-SANTOS, Cristina; MITCHELL, Paulo Vicente. Indicadores para avaliar a Segurança Alimentar e Nutricional e a garantia do Direito Humano à Alimentação: metodologias e fontes de dados. Anais, p. 1-21, 2016.

SANTILLI, Juliana. Agrobiodiversidade e direitos dos agricultores. São Paulo: Petrópolis, 2009.

SEN, Amartya. Desenvolvimento como liberdade. São Paulo: Companhia das Letras, 2010.

TRIOLA, Mário. Introdução à Estatística. 7. ed. Rio de Janeiro: LTC, 1999.

VEIGA, José. Eli da. A face territorial do desenvolvimento. Interações. Campo Grande, v. 3, n. 5 , set. 2002.

VIA CAMPESINA, La. La Via Campesina: international peasant's voice. Jakarta, Indonesia, 2011. Disponível em: <http://viacampesina.org/downloads/profiles/2011/BROCHURELVC2011-EN.pdf >. Acesso em: 21 maio 2017. 